\title{
Reform and Practice of Forestry Engineering Robot Course Based on Online and Offline Hybrid Teaching
}

\author{
Ying Xin ${ }^{a}$, Yaoxiang Li ${ }^{b}$, , Wei Xue ${ }^{c}$, Wenshu Lin ${ }^{d}$, Weiping Hou ${ }^{e}$ and Haiting $\mathrm{Di}^{\mathrm{f}}$ \\ College of Engineering and Technology, Northeast Forestry University, No.26 Hexing Road, \\ Xiangfang District, Harbin, 150040, China \\ axyneu2003@163.com, byaoxiangl@yahoo.com, ${ }^{\mathrm{c}} 3318281052 @ q q . c o m,{ }^{\mathrm{d}}$ linwenshu@126.com, \\ e7956909@qq.com, ${ }^{\mathrm{f}} 44713580 @ q q . c o m$ \\ *Corresponding author: yaoxiangl@yahoo.com
}

Keywords: Online and Offline, hybrid Teaching, forestry Engineering, robot

\begin{abstract}
At present, "Forestry Engineering Robot" course is a key curriculum that has gradually formed with the development of science and technology of forest colleges and universities, and has received the attention of relevant educators and students. To form on the online and offline synchronous teaching mode by taking the information technology as the carrier, students as the main body, problems as the center and teachers as the instructor. In fact, offline classroom teaching is the main body while online teaching is as a supplement, Forestry Engineering Robot teaching reform is carried out as useful exploration.
\end{abstract}

\section{Introduction}

With the development of network technology and the launch of online courses, the hybrid education approach has gradually focused on the combination of online teaching and offline classrooms. [1] Adopting the online and offline mixed teaching mode, we can take advantages of the abundant resources of online teaching courses, various teaching methods, and free learning time, break the shackles of traditional teaching, improve the teaching level and efficiency of the curriculum [2], and extend the time and space of the classroom, students can obtain the learning resources and realize the fragmented learning mode, learning is no longer limited by time and place.

The Forest Engineering Robotics course is the core course of forest engineering. The goal of teaching is to train students to use the basic theories and knowledge they have learned to realize the automatic transformation and innovative design of the original forestry machinery, and to master the design, performance analysis and control methods of forest industry robots. In the process of the course, the network information technology is used as the carrier to realize the combination of students self-learning and teachers guidance, implement online and offline synchronous teaching methods. [3] 


\section{Forestry Engineering Robot Curriculum Reform Based on Online and Offline Hybrid Teaching}

\subsection{Course Positioning}

Taking students as the center and using network information technology as the carrier, with the goal of "strengthening the foundation, attaching importance to application, cultivating ability, and improving quality" [4], we adhere to the teaching philosophy of "student as the main body, problem-centered, and teacher-led" to achieve student autonomic learning and teacher guidance, change teaching methods, implement online and offline synchronous teaching, share teaching resources, and effectively improve the learning environment, While students master the basic theoretical knowledge of forest industry robot, they can cultivate students' innovative thinking and autonomous learning ability through the guidance of cases and problems in the network course.

\subsection{Overall Curriculum Design}

According to the teaching objectives, the online and offline teaching activities of robot technology curriculum are reconstructed and divided into knowledge points, the situation of teaching activities is created, the corresponding teaching activities are designed for each teaching goal, and the supervision is permeated into the whole process of teaching activities. The Robotics Technology Course is based on the design of the online and offline mixed teaching mode of the flipping classroom. It insists on 'student-centered, students' autonomous learning-based" to strengthen students' learning ability, analytical problem-solving ability and application ability. [5]

(1) Course and Content Selection.

The construction of online courses chooses courses and contents purposefully according to teaching needs.

The training goal of Forest Industry Robot Technology Course is to cultivate students' comprehensive design ability and engineering practice ability, and the cultivation of these skills needs to run through the whole process of teaching. In the teaching content, the teaching reform and teaching research results and the latest development achievements of the discipline are introduced into the theoretical teaching and practical teaching in a timely manner. In the teaching process, create conditions for students to understand advanced robotics domestic and overseas to inspire their creative thinking and stimulate their creative desires; let students analyze the structure, function and control principles of typical robots, and gain an in-depth understanding of the frontiers and dynamics of robot development; use cases to combine the key and difficult points, and strengthen the coherence of knowledge learning while reducing the difficulty of learning ; let students propose improved design measures for the existing forest industry robot system to form a complete training process. Focusing on the three major matrices of robots, the theoretical contents of forward and inverse kinematics, micro-operations, and static balance are explained around the mapping relationship between the two spaces. In the process of explanation, the focus is on the integrity and practical application of the conclusions of the theoretical formula, and the derivation of the theoretical formula is not pursued too much, highlighting the "learning to use". In this way, not only the boring and tedious mathematical derivation can be avoided, but also the students can understand the background and engineering application of the theory, which ensure the integrity of the subject system.

(2) Online Course Design - Theoretical Teaching Organization

(1) Prepare Resources

The online course platform provides a variety of functions, such as knowledge point video, online assignment or test and correction, related links, online Q\&A and courseware teaching plan, 
which provides rich resources for the realization of online and offline hybrid teaching mode.

(2) Instructional Design

a) The purpose, focus and difficulty of teaching. Before students learn online, tell the teaching purpose, key points and difficulties on the teaching platform, so that students can have the direction of learning, at the same time, pay attention to the key and difficult contents, and achieve the teaching effect through students' self-study. [6]

b) Ask questions. In the teaching organization, the problem is thrown to the students, and the case teaching method is used to introduce the course content. In the process of online learning, students set up the question session and guide the students to achieve the learning objectives step by step through the solution of the problem.

c) Self-Exploration. For the question raised, it can be aimed at the content in the video, or it can be further deepened, requiring students to explore by themselves and find the answer. If the student finds that he has not achieved the purpose of teaching in the subsequent tests, and the key and difficult points were not grasped. He can explore and solve the problem through the relevant website links.

d) Self-Test. After the study, the students test themselves through the self-test module to find out their shortcomings. In the self-testing process, it is necessary to ensure that the students complete the test independently and ensure the test effect. The answers to the test are hidden in resources such as videos, teaching plans and so on. If the students fail to meet the requirements, they are forced to re-learn.

e) Online Discussion. For the gains or problems in the learning process, students can discuss in the discussion module, develop their ability to cooperate and deal with others through communication. At the same time, find out the problem so that the class can be presented to ask the teacher.

(3) Offline Course Design - Practical Teaching Organization

a) Students Question. For students through online autonomous learning and discussion of problems that can not be solved, it will be presented to the class teacher in the classroom. The teacher guides the students to think according to the mastery of the students, and finally gives a definite answer.

b) Student Groups Report. Under the condition that the students master the theory, the instructor will classify the robots and give each group a task. The team members work together to complete the collection of data, report the production of courseware, and ask students to explain the theoretical basis to help students realize the transformation from theory to practice, from knowledge to ability. In this process, teachers play the role of hosting, guiding, coordinating and summarizing, encouraging students to argue, discuss, and fully mobilize students' initiative.

c) Practice and Summary. Students use the information provided by the online course platform to practice exercises independently to cultivate their ability to analyze and solve problems. General problems are solved by mutual help between the students, and difficult problems are solved under the guidance of teachers.

(4) Teaching Effect Detection. Under the supervision of the teacher, the online course platform is used to test the students' learning results.

(5) Assessment and Evaluation Design. In the assessment and evaluation, students' performance in the process of learning and discussion, as well as online and offline exercises and test results are fully considered, the performance and test results in the offline classroom are taken as the main evaluation basis. 


\section{Difficulties in Promoting Online and Offline Hybrid Teaching Methods}

Through the online and offline teaching practice of forest engineering students in the two academic years of 2015 and 2016, it is found that the utilization rate of the online course platform is greatly improved, which promotes the enthusiasm of students to learn independently on the course platform, and the communication and interaction between teachers and students are more frequent. However, there are still the following problems in construction and application of online and offline hybrid teaching:

On the one hand, online and offline hybrid teaching poses greater challenges for teachers implementing the curriculum. The construction of the course network platform requires teachers to invest more time and energy. And the hybrid teaching design requires teachers to reorganize the teaching content and design the teaching links. Online and offline hybrid teaching requires fragmentation management of knowledge points, and the smooth implementation of high-quality micro-video is a guarantee of teaching. Therefore, college teachers should actively master modern information technology and online teaching tools, learn the curriculum platform construction and micro-video production knowledge and skills, and invest more energy to build online and offline curriculum platform resources.

On the other hand, students are accustomed to the traditional "cramming" teaching mode in the past, and can not adapt to the student-centered teaching mode of online courses. The understanding of the course platform is mainly limited to downloading courseware and materials. At the same time, some students can't manage and constrain their own online courses, and they can't complete this kind of self-study-based course learning greatly. This will require the teachers to strengthen the management and guidance of the network course, and to compare the learning time, the learning attitude and the learning content of the students in the course of the study.

\section{Conclusion}

In the teaching of "Forest Industry Robot Technology Foundation", students are the center, network information technology is used as the carrier, and the online and offline hybrid teaching mode is adopted, making use of the advantages of abundant network teaching course resources, various teaching methods and students' free learning time, breaking the shackles of traditional teaching, improving the teaching level and efficiency of the course, and extending the time and space of the classroom, and at the same time, after learning a chapter, you can use online resources to conduct online Q\&A and test students. Students can discuss and interact with each other, sharing learning experiences can improve students' active participation. At the same time, in the process of curriculum construction, new challenges are also raised for the design of teachers' teaching, the integration of teaching resources and the management of teaching.

\section{Acknowledgements}

The authors gratefully acknowledge the financial support from Teaching Reform of Heilong Jiang Province (SJGY20180011) and Heilong Jiang Province Education Science Plan Key Subject (GBB1317009).

\section{References}

[1] Huiqing Wu. PLC curriculum reform and practice based on online and offline blended teaching-Take Huaian Information Vocational and Technical College as an example [J]. Vocational Education, 2017 (18): 3-7.

[2]Ping Du. Application of online and offline interactive teaching mode in medical ethics teaching [J]. Chinese medical 
ethics, 2017 (7): 893-896.

[3] Pengxia Zhang, Jinbo Zhang, Qin Ou, etal. Construction and implementation of online and offline teaching mode of online course biochemistry [J]. Chinese journal of clinician, 2016 (23): 3853-3856.

[4] Zhengzheng Ma. Exploration and practice of the cultivation mode of applied talents in chemical engineering and technology [J]. Journal of jiamusi vocational college, 2020 (206): 226-227.

[5] Hongyuan Wu. Research on online course construction of accounting major in higher vocational colleges [J]. Vocational education communication, 2017 (6): 4-6.

[6] Yian Li, Fang Gao. The integration of flipped classroom and mooc promotes the balance of teaching resources [J]. Digital communication world, 2015 (156): 151. 